\title{
Analysis of drug prescriptions in primary health care centres in Bahrain
}

S. Otoom, ${ }^{1}$ K. Culligan, ${ }^{7}$ B. Al-Assoomi ${ }^{2}$ and T. Al-Ansari ${ }^{2}$

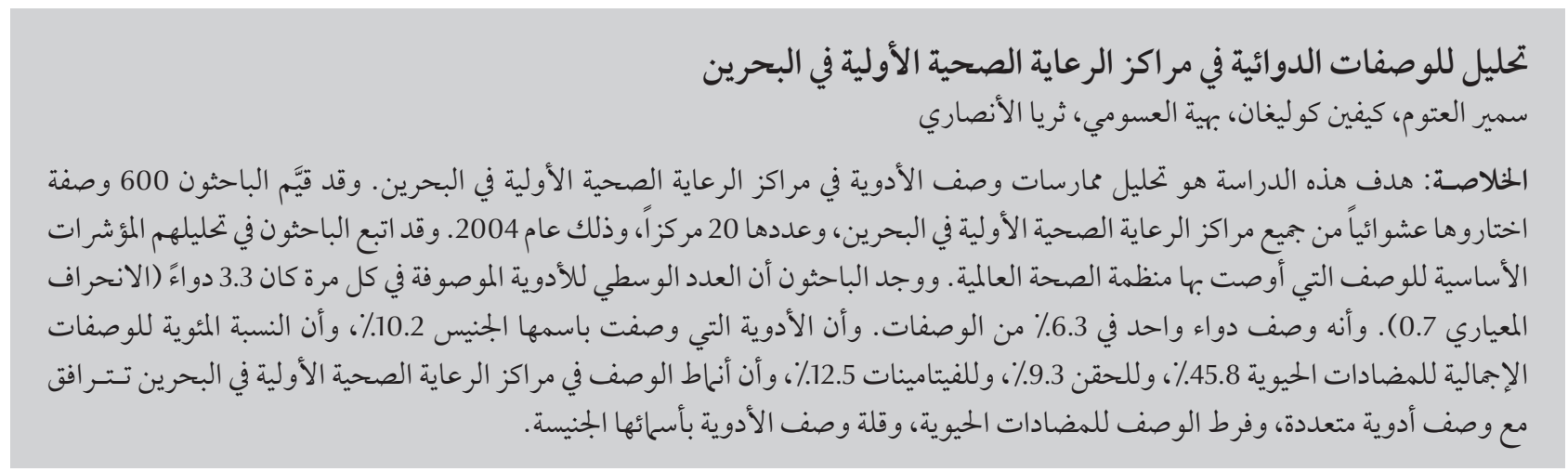

ABSTRACT The aim of this study was to analyse drug prescribing practices in primary health care centres in Bahrain. We retrospectively evaluated 600 prescriptions selected randomly from all primary health care centres in Bahrain $(n=20)$ in 2004. Analysis followed WHO recommended prescribing core indicators. The mean number of drugs prescribed at each encounter was 3.3 (SD 0.7). A single drug was prescribed on $6.3 \%$ of prescriptions and drugs were prescribed by generic name on $10.2 \%$. The percentage of total prescriptions for antibiotics was $45.8 \%$, for injections was $9.3 \%$ and for vitamins was $12.5 \%$. The prescribing pattern in primary health care centres in Bahrain is associated with polypharmacy, over-prescribing of antibiotics and an under-prescribing of drugs by generic names.

\section{Analyse des prescriptions médicamenteuses dans les centres de soins de santé primaires à Bahreïn}

RÉSUMÉ L'objectif de cette étude était d'analyser les pratiques en matière de prescription médicamenteuse dans les centres de soins de santé primaires à Bahreïn. Nous avons réalisé une évaluation rétrospective de 600 ordonnances choisies au hasard dans l'ensemble des centres de soins de santé primaires de Bahreïn $(n=20)$ en 2004. L'analyse s'appuyait sur les indicateurs fondamentaux de prescription recommandés par l'OMS. Le nombre moyen de médicaments prescrits lors de chaque consultation était de 3,3 (écart type 0,7). Dans 6,3\% des cas, un seul médicament était prescrit et 10,2\% des ordonnances portaient sur des médicaments prescrits par leur nom générique. Au total, $45,8 \%$, des prescriptions concernaient des antibiotiques, 9,3\% des injections et $12,5 \%$ des vitamines. Le mode de prescription des centres de soins de santé primaires à Bahreïn se caractérise par la polypharmacie, la surprescription d'antibiotiques et une sous-prescription des médicaments sous leur nom générique.

'Medical University of Bahrain, Royal College of Surgeons in Ireland, Busaiteen, Bahrain (Correspondence to S. Otoom: sotoom@rcsi-mub.com). ${ }^{2}$ Department of Primary Health Care Directorate, Ministry of Health, Manama, Bahrain.

Received: 05/06/07; accepted: 27/09/07 


\section{Introduction}

Evaluation of the quality of health care is an essential component of health system research [1]. Determination of the drug use indicators in a country, region or individual health facility allows health planners, managers and researchers to make basic comparisons between situations in different areas or at different times [2]. Three categories of indictors related to the rational use of drugs in primary care have been described: pharmaceutical prescribing practices by health providers; key elements of patient care; and availability of facilityspecific factors which support rational use [3].

Generally only a small number ofbasic or core indicators are recommended for national adoption and are included in any drug use study using indicators. Of these, the prescribing indicators are often used as a starting point in determining the core drug use indicators. The World Health Organization (WHO) has developed, standardized and validated a set of indicators to provide an appropriate means to evaluate a country's drug use patterns and to measure the efficacy of interventions [4].

Bahrain, with a population of 650000 , has a well organized primary health care service. A network of 20 health centres provides health care for all nationals and expatriates. Each health centre is staffed by 4-7 primary care physicians and other health care workers, is equipped with basic diagnostic facilities and contains both an operating theatre for minor surgical procedures and a pharmacy [5]. Essential drugs that should be available in all primary health care centres, known as the primary care list, are dispensed free of charge.

The aim of this study was to generate a descriptive analysis of the core indicators of prescribing in the health centres in Bahrain so as to guide further assessments and interventions.

\section{Methods}

\section{Sampling and data collection}

The total number of primary health care centres in Bahrain is 20. In each centre, at least 30 prescriptions were selected at random by an independent adjudicator from a database of prescriptions issued for acute medical conditions such as upper respiratory infection, headache and colic pain. These prescriptions, written during the year 2004, were retrospectively reviewed from patients' files and randomly selected to include 2 to 3 per month of that year. Each prescription reviewed was used as raw data for the study, recorded on forms designed according to the WHO recommendations for investigating core prescribing indicators.

Data collectors received training before undertaking the work where the aim of the study, the method to calculate the indicators and how to fill the forms were discussed. Prior to data collection, a 1-day pilot study was carried out at the Ministry of Health, Division of Primary Health Care, Bahrain. During this pilot, the study design and the approach of data collectors to the health care providers were tested. Feedback and comments from the data collectors were evaluated and incorporated as necessary into the study design.

\section{Calculation of indicators}

The recommended WHO core indicators [4] were calculated: mean number of drugs per encounter; percentage of total drugs prescribed by generic name; percentage of total patient encounters with an antibiotic prescribed; percentage of total encounters with an injection prescribed; and percentage of total encounters with vitamins prescribed. The percentage of drugs prescribed from the WHO list of essential medicines was not calculated as an essential medicines list is not used in Bahrain.

\section{Statistical analysis}

The data were analysed using SlideWrite Plus, version 4 statistical program. Data were expressed as means and standard deviations (SD).

\section{Results}

The number of prescription analysed was 600 . The mean age of the patients was 32.1 (SD 4.7) years, ranging across the health centres from a mean age of 22.7 to 38.6 years. The number of prescriptions taken from males and females in the sample was 280 and 320 respectively. Table 1 shows the results of prescription analysis for each health centre.

The overall mean number of drugs prescribed per patient encounter was 3.3 (SD 0.7), with a range of 2.0-4.6. The percentage of total prescriptions for a single drug was $6.3 \%$ and for drugs prescribed by generic name was $10.2 \%$ (range 0.0\%-23.1\%). The percentage of total prescriptions for antibiotics was $45.8 \%$ (range $26.7 \%-83.3 \%$ ), for injections was $9.3 \%$ (range $0.0 \%-20.0 \%$ ) and for vitamins was $12.5 \%$ (range $3.3 \%-23.3 \%)$.

Chi-squared tests showed no significant differences in the patterns of prescribing of antibiotics, injections and vitamins or in the rate of drugs prescribed by generic name.

\section{Discussion}

In the present study, data from 600 prescriptions from all 20 health centres in Bahrain, written in response to acute medical conditions, were analysed retrospectively according to the recommended WHO core indicators [4]. The mean age of patients identified in this study (32.1 years) is a reflection on the age structure of the population in Bahrain, with a large number of young expatriate workers. Using the WHO indicators, the mean number of drugs per 


\begin{tabular}{|c|c|c|c|c|c|c|}
\hline \multirow{3}{*}{$\begin{array}{l}\text { Health } \\
\text { centre no. }\end{array}$} & \multirow{3}{*}{$\begin{array}{l}\text { Patient age (years) } \\
\text { Mean (SD) }\end{array}$} & \multirow{3}{*}{$\begin{array}{l}\text { No. of drugs prescribed } \\
\text { per patient encounter } \\
\text { Mean (SD) }\end{array}$} & \multicolumn{3}{|c|}{$\%$ of patient encounters with prescription for: } & \multirow{3}{*}{$\begin{array}{l}\% \text { of drugs } \\
\text { prescribed by } \\
\text { generic name }\end{array}$} \\
\hline & & & Antibiotics & Injections & Vitamins & \\
\hline & & & & & & \\
\hline 1 & $23.6(17.1)$ & $2.2(1.1)$ & 30.0 & 13.3 & 3.3 & 4.5 \\
\hline 2 & $29.8(22.1)$ & $2.8(1.2)$ & 33.3 & 20.0 & 20.0 & 11.9 \\
\hline 3 & $31.5(19.5)$ & $3.8(1.7)$ & 50.0 & 10.0 & 20.0 & 12.4 \\
\hline 4 & $36.9(27.4)$ & $4.6(1.6)$ & 50.0 & 6.7 & 10.0 & 8.8 \\
\hline 5 & $29.4(18.6)$ & $3.6(0.7)$ & 53.3 & 0.0 & 23.3 & 11.1 \\
\hline 6 & $38.6(24.7)$ & $3.7(1.4)$ & 36.7 & 10.0 & 10.0 & 14.3 \\
\hline 7 & 31.7 (23.1) & $3.9(1.5)$ & 50.0 & 20.0 & 13.3 & 14.7 \\
\hline 8 & $33.3(21.2)$ & $2.6(1.8)$ & 63.3 & 3.3 & 16.7 & 23.1 \\
\hline 9 & $33.7(20.3)$ & $3.5(1.4)$ & 83.3 & 3.3 & 16.7 & 15.1 \\
\hline 10 & 37.3 (8.2) & $4.1(0.6)$ & 50.0 & 13.3 & 10.0 & 6.5 \\
\hline 11 & 36.4 (18.1) & $3.6(1.5)$ & 36.7 & 13.3 & 13.3 & 13.8 \\
\hline 12 & 30.7 (21.6) & $3.6(1.2)$ & 56.7 & 6.7 & 20.0 & 11.2 \\
\hline 13 & $34.1(24.2)$ & $4.0(1.3)$ & 66.7 & 13.3 & 3.3 & 11.7 \\
\hline 14 & $27.4(23.5)$ & $2.5(1.4)$ & 36.7 & 16.7 & 10.0 & 14.7 \\
\hline 15 & $37.2(20.5)$ & $2.7(2.0)$ & 33.3 & 6.7 & 10.0 & 0.0 \\
\hline 16 & $35.7(16.2)$ & $3.7(1.3)$ & 30.0 & 6.7 & 16.7 & 9.0 \\
\hline 17 & 22.7 (18.3) & $3.5(1.3)$ & 40.0 & 13.3 & 6.7 & 13.5 \\
\hline 18 & $28.3(19.1)$ & $2.4(1.2)$ & 50.0 & 6.7 & 10.0 & 4.1 \\
\hline 19 & 27.3 (15.8) & $2.0(0.9)$ & 26.7 & 3.3 & 13.3 & 1.6 \\
\hline 20 & $36.8(22.6)$ & $3.3(1.4)$ & 40.0 & 0.0 & 3.3 & 2.0 \\
\hline Total & $32.1(4.7)$ & $3.3(0.7)$ & 45.8 & 9.3 & 12.5 & 10.2 \\
\hline
\end{tabular}

$S D=$ standard deviation.

prescription was 3.3. The percentage of prescriptions with a single drug was only 6.3\%. This figure appears abnormally high when compared with other countries. For example, in the Asir region of Saudi Arabia the mean number of drugs prescribed per encounter was 1.44 [6]. One study of 12 developing countries demonstrated that the mean number of drugs prescribed was 1.6 [7]. Two countries (Indonesia and Nigeria) were excluded as their values (3.3 and 3.8 respectively) were attributed to irrational drug use, in particular to polypharmacy [7]. In Lagos, Nigeria, however, the implementation of rational drug use policies produced a significant decrease in the number of drugs prescribed 10 years later [8].

Prescribing by generic names of drugs was found to be very low in this study, with 1 health centre not prescribing any drugs generically. For only
$10.2 \%$ of the prescribed drugs was the generic name of the drug used. A similar result was observed in Karachi, Pakistan where consultants prescribed only $12 \%$ of drugs by generic name [9]. Our value was higher than that observed in Lebanon, where only $2.9 \%$ of prescriptions contained drugs prescribed by generic names [10]. This would reflect the minimal prescribing of generic drugs by physicians in primary health care facilities in Bahrain. Prescribing by generic names in other countries is high, with some countries prescribing solely by generic names. For example, in Niger, prescribing of drugs by generic name from the national drugs list is almost 100\% [11]. In Tanzania, $82 \%$ of prescribed drugs are by generic name, while $94 \%$ of drugs prescribed in Zimbabwe are by generic name [7].

It is apparent that this issue must be addressed. Generic drugs in Bahrain are generally of good quality and imported from drug companies that are approved by the United States Food and Drug Administration. The medical practitioners in Bahrain have graduated from different countries that know many drugs by brand names. Patients believe these drugs to be different from those available in the pharmacy of the primary health care centre and will buy them at their own expense. If these drugs are not available, physicians reported to our researchers that patients will argue about the efficacy of the alternative drugs. Additionally, pharmaceutical representatives in Bahrain provide incentives to medical practitioners to prescribe by brand name, a practice which the government tries to prevent. Moreover, the supply of a particular drug to primary health care centres in Bahrain can be from many sources not only through tenders but sometimes 
from local pharmacists when unexpected drug shortages occur. Enforcement of educational programmes and the development of a drug policy to enforce the prescribing of generic drugs should be implemented.

The percentage of encounters resulting in the prescribing of antibiotics was $45.8 \%$. This is low when compared with countries such as Jordan at $60.9 \%$ [12] and Sudan at 63\% [7]. In Saudi Arabia this figure was 56.2\% [6]. However, our figure is still relatively high. In Africa, Zimbabwe had a rate of $29 \%$ while Malawi had a rate of 34\% [7]. In the Middle East, Lebanon had a rate of $17.5 \%$ in a university health centre [10]. In Europe, Andorra had an antibiotic prescribing rate of $27 \%$ [13], while in central and South America Ecuador and Guatemala had rates of 27\% [7]. The excessive use of antibiotics has led to the emergence of bacterial resistance. The inappropriate use of antibiotics in clinical medicine is widespread, sometimes at inadequate dosages and often used for nonbacterial infections. This is more evident in the hospital setting where the use of antibiotics is maximal. The major reason for this is due to a lack of uniform policy, the lack of education and the over-the-counter availability of antibiotics in developing countries [12]. In private conversations our physicians explained the relative over-prescription of antibiotics as being due to the lack of standard treatment guidelines in Bahrain and due to patients' demands for antibiotics even in mild and viral infections. Demand can also be high when patients seek rapid amelioration of symptoms.

The proportion of encounters resulting in injections was 9.3\%. This is similar to values obtained in Nepal (5\%) and Zimbabwe (11\%) [7], although strikingly higher than that reported for the north of Jordan (1.2\%) [12]. Private conservations with our physicians confirmed that, as elsewhere in the region, patients have a preference for injections and believe that they are more effective than tablets, especially in the treatment of infections. When compared with both the international average of $17 \%$ and that of other countries in the developing world [7], the rate of injections in Bahrain is relatively lower.

In this study, the core drug use indicators in all 20 national primary health care centres of Bahrain were analysed. A similar study by Naseeb and Nasser was carried out in Bahrain [14]; however there are some notable differences. Although similar numbers of prescriptions were analysed, their study included only 4 primary health care centres by taking prescriptions of 1 day in 2003. Furthermore, the data obtained were analysed in the absence of prescribed medication for antenatal and dental procedures [14]. In spite of these differences, the data from both studies agree quite well. Naseeb and Nasser showed that the mean number of drugs per encounter was 2.6. The percentage of prescriptions containing injections and antibiotics was $8.3 \%$ and $26.2 \%$ respectively. The percentage of drugs prescribed by generic name was $14.3 \%$ [14]. Our study elaborates on their data, providing a more comprehensive analysis of the core drug indicators in all primary health care centres in Bahrain.

Like Naseeb and Nasser [14] we found overuse of antibiotics and underprescribing by generic names. However, in our larger study, a tendency towards polypharmacy was noted, with the total number of drugs prescribed averaging 3.3 compared with 2.6 for Naseeb and Nasser's study. Our analysis of all 20 health centres in Bahrain allows for a truer average, reducing centre-to-centre variability.

Rational drug use is well recognized as an important part of health policy. The rational use of drugs requires that patients receive medication appropriate to their clinical needs, in doses that meet their own requirements, for an adequate period of time and at the lowest cost to them and their community [15]. Studies suggest that over-prescribing, multi-drug prescribing, misuse of drugs, use of unnecessary expensive drugs and overuse of antibiotics and injections are the most common problems of irrational drug use by prescribers as well as consumers [16]. Although many efforts have been undertaken to improve drug use in developing countries, few evaluations have been done in this field.

Our evaluation of drug prescribing patterns in Bahrain primary health centres indicates that there is a clear need for medical education programmes in Bahrain which should promote the prescribing of drugs by generic names and encourage the rational use of drugs.

\section{Acknowledgements}

The authors would like to thank Professor Reginald Sequeira from the Department of Pharmacology and Therapeutics, Arabian Gulf University, Bahrain for his support throughout the study.

\section{References}

1. Venulet J. Rational prescribing of drugs. International journal of clinical pharmacology and biopharmacy, 1977, 15:151-4.

2. Laing RO. Rational drug use: an unsolved problem. Tropical doctor, 1990, 20:101-3.
3. Reguera G, Gomez V. Selección de indicadores para evaluar la adhesión a una guía farmacoterapéutica por los médicos generales de un área de atención primaria [Set of indicators for the assessment of the degree to which drug therapy guide 
is followed in primary care]. Revista española de salud pública, 2000, 74:65-80.

4. How to investigate drug use in health facilities: selected drug use indicators. Geneva, World Health Organization, 1993, 1:1-87 (WHO/DAP) (EDM Research Series No. 07).

5. Health statistics of 2004. Kingdom of Bahrain Ministry of Health [website] (http://www.moh.gov.bh/PDF/Publications/Statistics/hs2004/hs2004_e.html, accessed 1 June 2009).

6. Mahfouz AA et al. Prescribing patterns at primary health care level in the Asir region, Saudi Arabia: an epidemiologic study. Pharmacoepidemiology and drug safety, 1997, 6(3):197-201.

7. Hogerzeil HV et al. Field tests for rational drug use in twelve developing countries. Lancet, 1993, 342:1408-10.

8. Odusanya OO, Oyediran MA. The effect of an educational intervention on improving rational drug use. Nigerian postgraduate medical journal, 2004, 11(2):126-31.

9. Das $\mathrm{N}$ et al. Prescribing practices of consultants at Karachi, Pakistan. Journal of the Pakistan Medical Association, 2001, 51(2):74-7.

10. Hamadeh $\mathrm{GN}$ et al. Common prescriptions in ambulatory care in Lebanon. Annals of pharmacotherapy, 2001, 35(5):636-40.
11. Mallet HP, Njikam A, Scouflaire SM. valuation des habitudes de prescription et de l'usage rationnel des medicaments au Niger. Enquetes successives dans 19 centres de sante integres de la region de Tahoua [Evaluation of prescription practices and of the rational use of medicines in Niger]. Santé, 2001, 11(3):185-93.

12. Otoom $\mathrm{S}$ et al. Evaluation of drug use in Jordan using WHO prescribing indicators. Eastern Mediterranean health journal, 2002, 8(4\&5):537-42.

13. Vallano A et al. Medical specialty and pattern of medicines prescription. European journal of clinical pharmacology, 2004, 60(10):725-30.

14. Naseeb TA, Nasser MA. Drug prescribing indicators in primary health care centers in Bahrain. Saudi medical journal, 2005, 26(9):1436-8.

15. The rational use of drugs: report of the Conference of Experts, Nairobi, 25-19 November 1985. Geneva, World Health Organization, 1985.

16. Hogerzeil HV. Promoting rational prescribing, an international perspective. British journal of clinical pharmacology, 1995, 39:1-6.

\section{International Nonproprietary Names (INN) for pharmaceutical substances (CD-ROM)}

The International Nonproprietary Names (INN) for pharmaceutical substances CD-ROM lists all International Nonproprietary Names (INN) in Latin, English, French, Spanish, Arabic, Chinese and Russian published up to December 2009, together with references to the lists of proposed and recommended INN in which they have been published. It also includes references to other generic names, such as national nonproprietary names and names used by pharmacopoeial monographs, the List of Narcotic Drugs under International Control, and other sources. Indexes of molecular formulae and of Chemical Abstracts Services registry numbers are also included. Moreover it includes a searchable database of all INN published with their ATC codes and structures, as well as molecular formulae and CAS Registry Numbers.

Further information about this and other WHO publications can be found at: http://www.who.int/publications/en/ 